
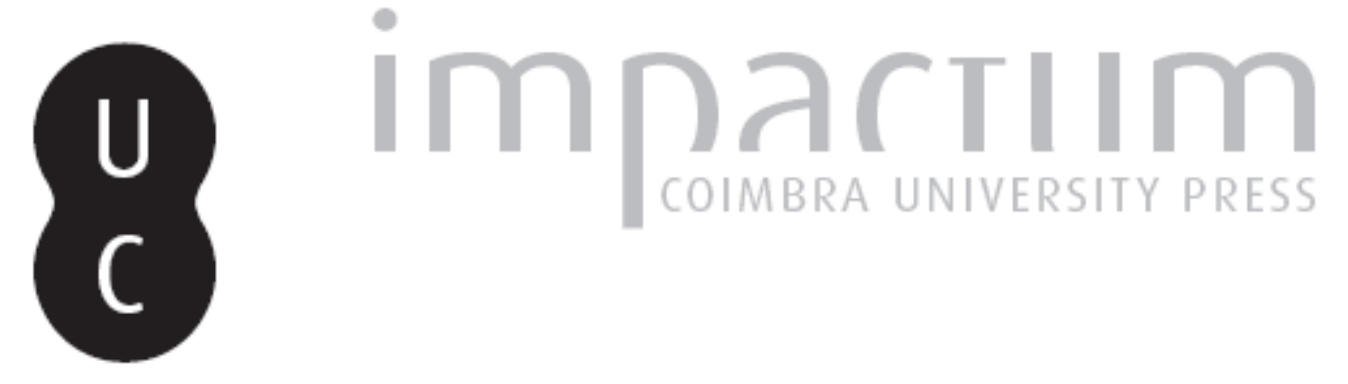

Ciência, identidade e quotidiano: alguns aspectos da presença de estudantes
brasileiros na Universidade de Coimbra, na conjuntura final do período colonial

Autor(es): $\quad$ Cruz, Ana Lúcia Rocha Barbalho da; Pereira, Magnus Roberto de Mello

Publicado por: Centro de História da Sociedade e da Cultura

URL

persistente:

URI:http://hdl.handle.net/10316.2/39583

DOI:

DOI:http://dx.doi.org/10.14195/1645-2259_9_8

Accessed : $\quad$ 26-Apr-2023 14:17:11

A navegação consulta e descarregamento dos títulos inseridos nas Bibliotecas Digitais UC Digitalis, UC Pombalina e UC Impactum, pressupõem a aceitação plena e sem reservas dos Termos e Condições de Uso destas Bibliotecas Digitais, disponíveis em https://digitalis.uc.pt/pt-pt/termos.

Conforme exposto nos referidos Termos e Condições de Uso, o descarregamento de títulos de acesso restrito requer uma licença válida de autorização devendo o utilizador aceder ao(s) documento(s) a partir de um endereço de IP da instituição detentora da supramencionada licença.

Ao utilizador é apenas permitido o descarregamento para uso pessoal, pelo que o emprego do(s) título(s) descarregado(s) para outro fim, designadamente comercial, carece de autorização do respetivo autor ou editor da obra.

Na medida em que todas as obras da UC Digitalis se encontram protegidas pelo Código do Direito de Autor e Direitos Conexos e demais legislação aplicável, toda a cópia, parcial ou total, deste documento, nos casos em que é legalmente admitida, deverá conter ou fazer-se acompanhar por este aviso.

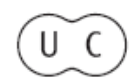



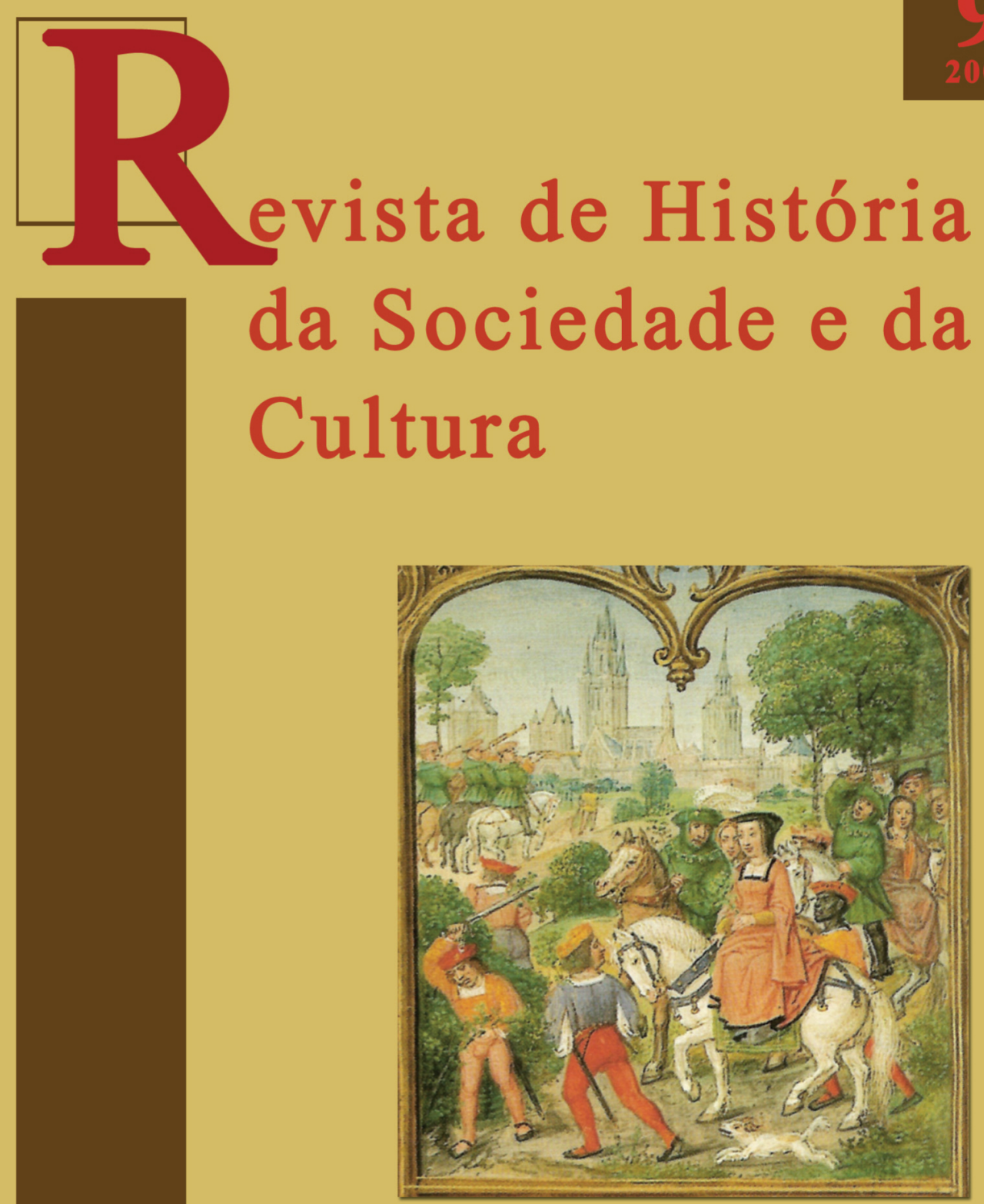

Centro de História da Sociedade e da Cultura Universidade de Coimbra

Coimbra 


\title{
Ciência, identidade e quotidiano. Alguns aspectos da presença de estudantes brasileiros na Universidade de Coimbra, na conjuntura final do período colonial ${ }^{*}$
}

\author{
Ana Lúcia Rocha Barbalho da Cruz \\ Centro de Documentação e Pesquisa de História dos Domínios Portugueses da \\ Universidade Federal do Paraná (Brasil) \\ analucia.cruz@hotmail.com \\ e \\ Magnus Roberto de Mello Pereira \\ Universidade Federal do Paraná (Brasil) e Centro de Documentação e Pesquisa de \\ História dos Domínios Portugueses \\ magnus@ufpr.br
}

Texto entregue em/Text submited on: 13/04/2009

\section{Resumo/Abstract:}

No final do século XVIII e início do século XIX, a administração portuguesa conduziu uma política de cooptação dos filhos da elite luso-brasileira, incentivando a sua formação académica na Universidade de Coimbra. Muitos deles viriam a ter posições de destaque no período do Reino Unido e, depois, nos primeiros anos do Brasil independente. O presente artigo pretende acompanhar alguns aspectos identitários e da vida quotidiana revelados na passagem desses intelectuais por Coimbra.

In the late $18^{\text {th }}$ century and early $19^{\text {th }}$ century, the Portuguese administration implemented a policy encouraging the sons of the Portuguese-Brazilian elite to attend Coimbra University. Many of them later held high offices during the period of the United Kingdom of Portugal, Brazil and Algarve and, afterwards, in independent Brazil. This paper tries to analyse some aspects of their identity and daily lives revealed during their stay in Coimbra.

Palavras chave/Key words:

Identidade Brasileira; Elite intelectual luso-brasileira; Universidade de Coimbra.

Brazilian identity, Portuguese-Brazilian intellectual elite, Coimbra University.

* Este artigo é resultado de pesquisas financiadas pelas seguintes agências de fomento: Fundación Carolina, CAPES, CNPq e Fundação Araucária. 


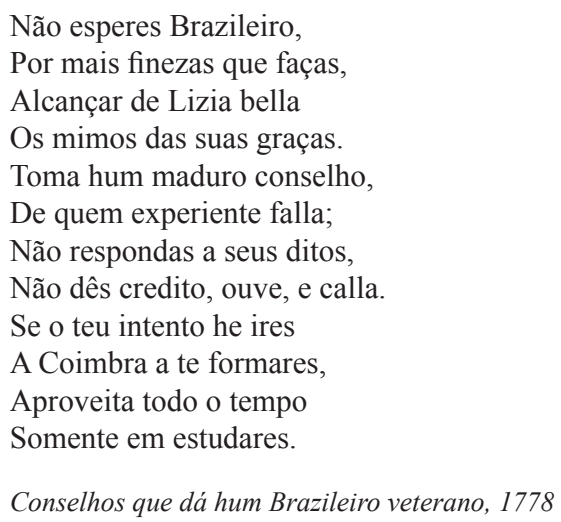

$\mathrm{Na}$ ausência de instituições de ensino superior em terras da colónia brasileira, a alternativa que se apresentava para os filhos da elite colonial era a formação académica na Universidade de Coimbra. Podemos imaginar que o interesse dos colonos abastados em enviar seus filhos para estudarem em Portugal fosse, para além de propiciar-lhes alternativas de profissionalização, uma forma de promover o estreitamento de laços com a metrópole, visando a obtenção de benesses ulteriores.

Por outro lado, havia a sede de um imenso império que, temendo perder seus domínios no ultramar, procurava cooptar as elites coloniais para seu projecto de reformas e modernização. Uma das estratégias para tal foi a criação de estímulos e facilidades para que os filhos das famílias mais abastadas fizessem seus estudos em Coimbra, acreditando-se ser a educação poderoso elemento de unificação ideológica. "Quase toda a elite possuía estudos superiores, o que acontecia com pouca gente fora dela: a elite era uma ilha de letrados num mar de analfabetos"'. Sabendo-se que a colônia americana era, nesse momento, a melhor parte do Império e levando-se em conta o receio de que as idéias revolucionárias da Europa continental contaminassem os 'homens bons' da sua melhor colônia, Portugal procurou aportar a juventude da colônia do Brasil na sua 'ilha de letrados', preparando-a para assumir serviços de reconhecimento e governação imperiais.

1 CARVALHO, José Murilo de - A construção da ordem; a elite política imperial. Rio de Janeiro: Campus, 1980. p. 51. 
O impedimento da abertura de cursos superiores no Brasil pode ser visto como uma das partes visíveis dessa estratégia, cuja contrapartida mais imediata foi a distribuição de cargos no governo para os alunos egressos da Universidade Coimbra. Assim, desde a reforma da Universidade (1772), o aparelho administrativo português passará a absorver um número crescente de académicos de origem brasileira. Durante o período em que D. Rodrigo de Souza Coutinho ocupou a pasta dos Negócios do Ultramar, é notável a presença de nascidos no Brasil sob as ordens imediatas do ministro. Ele irá rodear-se de um grupo influente de intelectuais originários da América portuguesa, como José Bonifácio e José da Silva Lisboa. Após um curto período de declínio, D. Rodrigo volta ao poder, justamente na conjuntura da vinda da família real para o Brasil, e com ele os seus quadros científicos e administrativos brasileiros. A título de exemplo pode-se tomar o caso de Minas Gerais, onde, no final do período colonial, 34 cientistas conimbricenses ocupavam cargos públicos, alguns deles comissionados pelo governo imperial, para levantar potencialidades económicas, principalmente dos recursos vegetais e minerais ${ }^{2}$. O presente artigo detem-se no estudo de alguns aspectos da passagem desta intelectualidade por Coimbra.

O número de alunos brasileiros constantes na relação de matrículas da Universidade, elaborada por Francisco de Morais, confirma a eficácia da estratégia da coroa portuguesa para atrair a juventude brasileira para a formação superior na Coimbra reformada ${ }^{3}$. Entre 1772-1808, período balizado pela reforma do ensino superior e a vinda da família real para o Brasil, 608 brasileiros teriam passado pelos bancos da Universidade portuguesa. É interessante notar, porém, que a distribuição desses alunos entre os diversos cursos guarda algumas peculiaridades, em especial a acentuada opção por carreiras científicas, diga-se Filosofia (que habilitava em ciências Naturais), e Matemática (que habilitava em Astronomia).

Essas preferências iam ao encontro daquilo que pretendia o Marquês de Pombal com a reforma da Universidade de Coimbra: a formação de uma elite restrita de profissionais com habilitação científica. Para ele, não

2 CARVALHO - A construção, cit. p. 54.

3 MORAIS, Francisco de - Estudantes brasileiros na Universidade de Coimbra. Anais da Biblioteca Nacional. 62 (1940) 137-335. 
interessava que a Universidade ultrapassasse em muito os 1.200 alunos, "porque os quatro mil (na maior parte bolônios) que até aqui se matriculavam seriam prejudiciais ao reino, faltando nele homens para as outras profissões; não podendo haver lugar para todos, e ficando com a sua ociosidade fazendo perturbações entre seus compatriotas." ${ }^{4}$ Nesse contexto de pretendida redução da população escolar, crescem em importância e significado os mecanismos de atracção de alunos oriundos do Brasil. Sérgio Buarque de Holanda não deixou passar desapercebido o resultado dessa opção, o qual ele qualificou de "chusma de naturais do Brasil que então se devotam afincadamente às "realidades práticas' e às próprias Ciências aplicadas." Para Holanda, no entanto, tratava-se de uma tendência que se manifestara naturalmente e não como o resultado de uma política coerente, orientada a partir de Lisboa. ${ }^{6}$

Um rápido exame do quantitativo da presença luso-brasileira em Coimbra dá-nos uma ideia da magnitude das transformações ocorridas naquele momento. Antes, e mesmo depois da Reforma, os cursos de Cânones e Leis reuniam o grosso da população estudantil de Coimbra, embora, após a Reforma, a percentagem de alunos dos cursos jurídicos tenha caído de cerca de $80 \%$, para não mais que $52 \%$. Tal queda pode ser atribuída aos contingentes dos novos cursos de Matemática e Filosofia, que chegaram a 408 alunos obrigados e 17 ordinários, entre os anos de 1773-747. Para o mesmo período, entre os ordinários, seis eram brasileiros. Entre 1772 e 1808, de um total de 608 brasileiros matriculados, cinquenta e cinco teriam optado por fazer os cursos de Matemática e/ou Filosofia na qualidade de

${ }^{4}$ Carta de Pombal para o reitor reformador Francisco de Lemos de Faria Pereira Coutinho, datada de Novembro de 1772, citada a partir de BRAGA, Teophilo - História da Universidade de Coimbra nas suas relações com a instrução pública portuguesa. Lisboa: Tipografia da Academia Real das Ciências, 1898, vol. 3, p. 449-450.

5 HOLANDA, Sérgio Buarque - Apresentação in COUTINHO, Joaquim de Azeredo Obras econômicas de J. J. da Cunha Azeredo Coutinho (1794-1804). São Paulo: Companhia Editora Nacional, 1966, p. 14.

6 Sobre a percepção do fenômeno na historiografia brasileira ver PEREIRA, Magnus R. M. e CRUZ, Ana Lúcia Rocha Barbalho da - A historia de uma ausência: Os colonos cientistas da América Portuguesa na historiografia brasileira. In FRAGOSO, João et al. (Orgs.) - Nas rotas do Império. Vitória/Lisboa: Edufes/IICT, 2006. p.357-389.

FONSECA, Fernando Taveira da - A Universidade de Coimbra (1700-1771); estudo social e económico. Coimbra: Universidade de Coimbra, 1995, p. 51. 
ordinários. Os números crescem para 102, quando considerados, para o mesmo período, os alunos que, na listagem de Morais, têm registo apenas como obrigados dos cursos de Matemática, Filosofia, ou ambos. Esses quantitativos, evidentemente, não reflectem todo o universo de brasileiros que passaram pelas aulas de Vandelli, de Dalla Bella ou de Miguel Ciera, uma vez que, entre os alunos de Direito, de Medicina e mesmo de Teologia, a grande maioria frequentou as disciplinas das Ciências da Natureza como preparação obrigatória para os cursos escolhidos. A contrapartida que levava a esse tipo de escolha nas matrículas eram os desejados empregos públicos. As profissões de naturalista e de matemático estavam em alta na conjuntura da política educacional pombalina.

Alexandre Rodrigues Ferreira, João da Silva Feijó, Francisco José de Lacerda e Almeida, António Pires da Silva Pontes, entre outros, formaram a primeira geração de cientistas modernos do mundo português, enviados nas expedições demarcatórias e nas viagens filosóficas aos territórios coloniais dos diversos continentes ${ }^{8}$. No entanto, esses brasileiros que tomaram parte nas expedições científicas de Setecentos, após terem feito seus estudos na Coimbra reformada, são apenas a parte mais visível da estratégia portuguesa da incorporação de luso-brasileiros no processo de co-gestão colonial, através da formação científica ${ }^{9}$. Fragmentariamente é possível localizar algumas centenas de nomes de outros ex-estudantes conimbricenses envolvidos no mesmo processo. Na década de 1940, o estudo pioneiro de Francisco de Morais deu contornos mais nítidos a um fenómeno que, até então, era mais intuído do que conhecido ${ }^{10}$. Ao fechar o século XX, o estudo quantitativo da presença brasileira em Coimbra ganhou peso com um trabalho magistral

A inserção desses novos personagens científicos, naturalistas e astrônomos, na cena administrativa portuguesa não ocorreu sem dificuldades, ver PEREIRA, Magnus Roberto de Mello. - Um jovem naturalista num ninho de cobras: a trajetória de João da Silva Feijó em Cabo Verde, em finais do século XVIII. História: Questões \& Debates. 36 (2002) 28-60.

9 Sobre a participação de brasileiros na rede de informações científicas montadas pela coroa portuguesa ver KURY, Lorelai - Homens da ciência no Brasil: impérios coloniais e circulação de informações (1780-1810). História, Ciências, Saúde. 8 suplemento (2001) 109-129 e DOMINGUES, Ângela - Para um melhor conhecimento dos domínios coloniais: a constituição de redes de informação no Império português em finais do Setecentos. História, Ciências, Saúde. 8 suplemento (2001) 823-838.

${ }^{10}$ MORAIS - Estudantes..., cit. 
de autoria de Fernando Taveira da Fonseca ${ }^{11}$. Muitos dos ex-conimbricenses formariam a primeira geração de quadros públicos do Brasil independente, como já assinalaram José Murilo de Carvalho e outros estudiosos. O que falta, para que tenhamos uma melhor compreensão do processo, são estudos sistemáticos sobre as carreiras dos egressos de Coimbra. Em suma, falta saber o que foi feito dos mais de 1.000 luso-brasileiros que passaram pela Universidade nos últimos 50 anos do período colonial. Falta, também, acompanhar mais de perto a formação dessas camadas intelectualizadas.

O presente artigo insere-se nesta busca, mas numa perspectiva assumidamente impressionista. Apoia-se maioritariamente em fontes indirectas e pretende mais apontar para possibilidades futuras de desenvolvimento do tema do que traçar qualquer percurso conclusivo sobre a presença dos luso-brasileiros em Coimbra.

Revisões historiográficas recentes têm demonstrado o quanto é descabido pensarmos em termos de Brasil antes de existir a nação brasileira independente. Em decorrência, tem ocorrido uma aproximação entre as historiografias brasileira e portuguesa e o reenquadramento do Brasil colónia no contexto imperial português. Neste contexto, o estudo da complexa questão identitária luso-brasileira tem ocupado papel de relevo ${ }^{12}$. Mas de que identidade estamos tratando? O artigo busca acompanhar alguns aspectos da presença de um grupo de actores que terão presença determinante na concepção, primeiro, de um grande império luso capaz de acolher os interesses das elites coloniais e, depois, na constituição do império independente brasileiro ${ }^{13}$. Contudo, os aspectos estudados não têm o carácter grave do envolvimento desses jovens coloniais nas questões políticas e económicas. Trata-se, antes, de os acompanhar em alguns momentos da vida quotidiana de estudantes de

${ }^{11}$ FONSECA, Fernando Taveira da - Scientiae thesaurus mirabilis; estudantes de origem brasileira na Universidade de Coimbra. 1601-1850. Revista Portuguesa de História. 33 (1999) 527-59.

${ }^{12}$ Ver CRUZ, Ana Lúcia Rocha Barbalho - As viagens são os viajantes: dimensões identitárias dos viajantes naturalistas brasileiros do século XVIII. História: Questões e Debates. 36 (2002) 61-98. JANCSO, István e PIMENTA, João Paulo - Peças de um mosaico; ou apontamentos para a emergência da identidade nacional brasileira. Revista de História das Ideias. 21 (2000) 398-440.

${ }^{13}$ Ver LYRA, Maria de Lourdes Viana - A utopia do poderoso império. Rio de Janeiro: Sete Letras, 1994. 
Coimbra, na trajectória de se fazerem "doutores", componente identitária que carregarão pelo resto de suas vidas.

\section{Viver em Coimbra}

Para se tornarem doutores em Coimbra era necessário, no entanto, viver por alguns anos na cidade, o que não se revelava fácil para muitos dos naturais das colónias. De qualquer parte que se viesse, não era simples alcançar a cidade. As estradas eram difíceis e constituía mesmo uma aventura a viagem até lá. Basta dizer que, para vencer as 33 léguas que a separavam de Lisboa, levava-se cerca de 2 dias. Dependendo da terra de origem, mesmo os estudantes reinóis tinham que enfrentar penosas jornadas em lombos de mula, até atravessar a ponte sobre o Mondego e entrar em Coimbra. Quanto aos brasileiros, passavam não menos de 60 dias para cruzar o Atlântico até ao porto de Lisboa e daí, até ao destino, mais uma difícil jornada por terra.

Se, por um lado, estudar em Coimbra significava para os estudantes do ultramar enfrentar as dificuldades do viver longe da casa paterna, por outro, constituía oportunidade de estreitar relações com conterrâneos, travar contacto com jovens de outras partes do Brasil e formar com eles laços de solidariedade. Esse aspecto não será irrelevante ao observarmos os desdobramentos que essa rede de solidariedades regionais propiciou, em termos da agregação dos estudantes brasileiros em torno dos novos espaços de sociabilidade que o universo académico e o viver na metrópole ofereciam.

Algumas famílias enviavam para Coimbra mais do que um filho, e não era incomum rapazes da mesma região seguirem juntos para a metrópole. As famílias abastadas chegavam a manter dois e até três filhos na cidade, como é o caso de Agostinho Delgado Arouche que, em 1774, para lá enviou seus filhos Diogo, José e Francisco Leandro. Alexandre Rodrigues Ferreira também seguiu para Coimbra na companhia do irmão Bartolomeu, e Baltasar da Silva Lisboa iria encontrar-se com seu irmão mais velho, José da Silva Lisboa, dois anos após este ter entrado na Universidade. A engrossar o grupo dos baianos, Joaquim de Amorim e Castro chegaria a Coimbra para 
matricular-se na Universidade, no mesmo ano em que seu conterrâneo Baltasar da Silva Lisboa.

Levando em conta que, mesmo para os padrões de finais do século XVIII, Coimbra era uma pequena cidade, e considerando ainda que a comunidade académica constituía um grupo diferenciado no interior da cidade, não é difícil imaginar a convivência entre os contemporâneos brasileiros que formariam uma rede de solidariedade entre pares.

O historiador Russel-Wood localizou uma colecção de cartas de um estudante de Coimbra para seu pai na Bahia. Esta documentação é um dos raros registos encontrados relativos ao testemunho directo de um estudante brasileiro vivendo na cidade do Mondego ${ }^{14}$. Embora a única das cartas publicadas pelo autor do artigo seja datada de um período anterior ao enfocado neste trabalho, sabe-se que as precárias condições da pequena Coimbra para abrigar seus estudantes perduraria por todo o século XVIII. Após a reforma de 1772, quando a obrigatoriedade da presença dos alunos para procederem aos dois períodos de matrículas anuais e uma maior exigência de comparecimento às aulas forçavam a permanência dos estudantes na cidade, as dificuldades para encontrar acomodação tornaram-se maiores. Nesse período, tentou-se impor a recuperação das antigas casas da Almedina, num esforço de viabilizar hospedagem para os estudantes que chegavam de todas as partes do império. De qualquer modo, segundo Taveira da Fonseca, Coimbra "dificilmente poderia absorver - alojando e alimentando em permanência - a totalidades dos matriculados", sendo parte da população estudantil sempre "itinerante". "Serão sobretudo os estudantes oriundos das regiões mais distantes (incluindo os ultramarinos) os que ficam em Coimbra"15.

Entre estes, parece ter sido corrente os veteranos abrigarem em suas casas os conterrâneos recém chegados. Hipótese que os estudos de António de Oliveira confirmam: "Embora a Almedina constituísse o centro da morada

${ }^{14}$ RUSSELL-WOOD, A. J. - Relato de um caso Luso-Brasileiro do século dezassete. Studia. 36 (1973) 7-38. A lamentar a publicação de apenas uma das 11 cartas de António Alvares Pereira a seu pai, Manuel Alvares Pereira. O autor localizou ainda cinco cartas do estudante para Manuel de Sousa Madeira, colega comercial de seu pai.

${ }^{15}$ FONSECA, A Universidade..., cit., p. 368-369. 
dos estudantes, havia uma certa tendência para se agruparem de acordo com as proximidades geográficas das origens" $"$.

Foi o que aconteceu com um estudante baiano referido por Russel-Wood. Ao chegar a Coimbra, em 1695, António Álvares Pereira e o amigo Francisco Ribeiro buscaram logo a casa do também brasileiro Lucas Ribeiro. Percebe-se que as identificações de origem constituiam, em princípio, um importante factor de agregação dos estudantes e de adaptação ao novo ambiente. António escreveu ao pai dizendo que logo que chegara, "a sala se cobriu de estudantes a fazerem o que costumam aos que vão novatos, e nos trataram com melhor modo e brandura do que imaginávamos."17 Antonio tranquilizava o pai, dizendo que ele, Francisco e o hospedeiro Lucas "parecemos três irmãos". É lícito supor que a prática dos jovens brasileiros recém chegados travarem contacto com seus compatriotas veteranos tenha permanecido ao longo dos anos.

A adaptação ao novo ambiente não seria fácil. No caso dos brasileiros, as dificuldades começavam com o impacto do próprio clima do hemisfério Norte, cujas baixas temperaturas do Inverno eram inusitadas para os oriundos dos trópicos. O estudante António queixava-se ao pai dos rigores do Inverno de Coimbra: “[...] o frio que há nesta terra é insuportável, e sempre estamos juntos ao fogareiro, e andamos tremendo com os pés cheios de frieiras, as unhas das mãos e dos pés parecem que saltam fora, tudo é gemer, tudo tremer, e não pode uma pessoa fazer nada por amor do frio que é o mal que tem Portugal." 18

Para esse estudante baiano, filho de um rico comerciante exportador, estar longe da pátria e do conforto da casa paterna onde, certamente, contava com negros e negras para o servirem, estar em Coimbra, entregue à própria sorte, constituía sacrifício comparável ao de um exílio. Grande parte da

${ }^{16}$ OLIVEIRA, António de - O quotidiano da Academia in História da Universidade em Portugal (1537-1771). Coimbra: Universidade de Coimbra; Fundação Calouste Gulbenkian, 1997, vol. 1, tomo 2, p. 624.

17 As fontes referem-se com frequência à violência das "investidas" dos veteranos contra os novatos de Coimbra. Ser recebido por um conterrâneo talvez pudesse atenuar o rigor das recepções académicas aos caloiros. Sobre a prática do trote ou praxe académica, ver o opúsculo do estudante paraense PATRONI, Filippe Alberto - Dissertação sobre o direito de caçoar, que compete aos veteranos das academias. Lisboa: Impressão Régia, 1818.

${ }^{18}$ RUSSELL-WOOD, A. J. - Relato..., cit., p. 35. 
referida carta de António ao pai é gasta em lamentações. "[...] não sei a VM encarecer em que miséria está esta terra pela falta de mantimentos [...] quando me alevanto da mesa saio morrendo a fome, não há haver galinhas nem frangos [...]. Coimbra só para degredados serve, pela fome, doenças e frios $[\ldots]^{\prime \prime 19}$.

Instalado em Coimbra, António encaminhou ao pai um rol de encomendas. Pedia "do sertão, alguns rolos de cera" (para iluminar as noites de estudo), um barril de farinha (provavelmente a de mandioca) e outro de arroz, tudo para consumo próprio. Pedia açúcar, para "dar de "mimo" a "alguns fidalgos" a quem devia favores. Para fazer frente aos rigores do Inverno, pediu meias de algodão. Exigente, o estudante queria ainda "um sinete de marfim bom, e se não for bom, não mo mande" e alguns rosários, contanto que fossem bem feitos. Curiosidades da terra também seriam benvindas, como "algumas contas de peixe mulher" e também as novidades: "mande algumas moedas novas para vermos, que os filhos da Bahia estão com grandes desejos de as ver". Se houvesse algum "estudante conhecido" por vir, este poderia ser portador de algumas superfluidades: "tabaco do bom”, lenços finos da Índia, lenços de cambraia ("de outra coisa não servem”), com uma bainha de um dedo de largura por toda a roda, feitos conforme "a moda que cá se usa" ${ }^{20}$. Porém, este estudante bem nascido e com certa afectação de janota sentia a mesma falta que acometia a quase todos os estudantes forasteiros: dinheiro $^{21}$. Em Coimbra, diferentemente do Brasil, onde as famílias abastadas contavam com escravos para servi-las, o estudante tinha que pagar por tudo: moradia, comida, roupas, serviços vários (como lavagem de roupa, conserto de sapatos, etc.), livros, apostilas, móveis e utensílios de uso diário, como pratos, talheres, etc. De entre os pedidos ao pai, António asseverava

${ }^{19}$ Idem, p. 35-36.

${ }^{20}$ Idem, p. 37.

${ }^{21}$ O pai de António Álvares Pereira, Manuel Álvares Pereira, foi um bem sucedido homem de negócios da Bahia, com actividades na área da pecuária e do comércio (exportava para Portugal, Angola, ilhas Atlânticas e região do rio da Prata). Também exerceu cargos burocráticos: tesoureiro da Irmandade do Santíssimo Sacramento da Sé da Bahia, procurador do Convento do Desterro, moedeiro e tesoureiro da Casa da Moeda da Bahia, "juiz e escrivão da segunda frota" e encarregado da arrecadação do tabaco em pó, ver Russel-Wood Relato..., cit., p. 25-27. Embora o autor afirme que Manuel gozou de "êxito modesto" nas suas actividades, somos levados a crer que, de facto, se tratou de um negociante de grosso trato da emergente camada de comerciantes baianos. 
que o mais necessário era dinheiro, pois, "tudo nos custa dinheiro, tudo, sem exceção de nada".

As mazelas do estudante estão registadas em várias composições do Palito Métrico nas quais os dissabores estudantis são anunciados em títulos explicativos ${ }^{22}$, como este:

"Queixas de Amaro Mendes Gaveta, estudante na Universidade de Coimbra, contra pulgas, percevejos, bêstas de jornada, arrieiros, estalajadeiros, lograntes, amas, moços, lavadeiras, ruas, falta de divertimentos, etc. Escritas em oitavas portuguesas e dedicadas aos nobilíssimos e preclaríssimos Pais dos Senhores Estudantes Conimbricenses, para que vindo no conhecimento dos muitos trabalhos, que seus estudiosos filhos padecem nas jornadas, e Universidade, se dignem a lhes acrescentar as mezadas, por Domingos Gonçalves Perdigoto, vizinho do tal Amaro Mendes Gaveta e assistente debaixo dos seus quartos." 23

Noutra composição do Palito Métrico, o autor menciona que "a primeira cousa que fazem os Pais ricos, quando intentam mandar seus filhos à Universidade, é procurar alguma via, ou correspondente, por quem thes possam contribuir as mesadas, ou lhas dão logo todas juntas por evitarem este trabalho." ${ }^{24} \mathrm{O}$ comerciante lisboeta Manuel de Sousa Madeira tinha ordens do pai de António Álvares Pereira para provê-lo do que fosse necessário. No rol de despesas efectuadas com o jovem recém chegado constam despesas com "aviamentos" feitos em Lisboa à chegada do estudante, gastos com o transporte em bestas de Lisboa a Coimbra, $78 \$ 000$ réis de mesada anual, à razão de $6 \$ 000$ réis por mês, acrescidas de $12 \$ 000$ réis de "mesadas suplementares" 25 . Antonio, seguramente, reunia as características

${ }^{22}$ Trata-se de uma colectânea de textos jocosos, datados do século XVIII, produzidos por estudantes de Coimbra. Pouco ou nada conhecido no Brasil, o Palito Métrico ou Macarronea Latino-Portuguesa tem sido bastante utilizado por pesquisadores portugueses a propósito da vida estudantil na Coimbra setecentista.

${ }^{23}$ Palito Métrico e correlativa macarrónea latino-portuguesa. Coimbra: Coimbra Editora, 1942, p. 234-273.

${ }^{24}$ Palito Métrico..., cit., p. 163-164.

${ }^{25}$ RUSSEL-WOOD, A. J. - Relato..., cit., p. 36. 
do estereótipo de estudante rico de que trata o Palito Métrico, "aqueles que têm cinco moedas de mesada, [...]filhos de mercadores ricos, ou [...] brasileiros, que têm letra aberta no correspondente. ${ }^{26}$ Ainda assim, António queixava-se de falta de dinheiro.

Para o caso dos estudantes brasileiros de Setecentos, infelizmente, não foi possível localizar correspondência para as famílias, fonte preciosa para nos acercarmos de seu viver quotidiano na cidade do Mondego. Entretanto, ao tratar do arrendamento de casas em Coimbra, no ano de 1787, Taveira da Fonseca menciona Manuel Ferreira da Câmara que "tinha à sua conta um sobrado e ainda dois andares e um sobrado, e por tudo pagava 36.400 réis [...]"27. Provavelmente, trata-se do mineiro, que viria a tornar-se importante mineralogista da Coroa e, posteriormente, intendente da demarcação diamantina. Juntamente com José Bonifácio de Andrada foi enviado em viagem de instrucção para diversas partes da Europa. Ferreira da Câmara era um daqueles brasileiros abastados a quem foi possível viver em Coimbra com invulgar largueza.

\section{Pátrias Chicas}

No imaginário académico, o local de origem dos estudantes era utilizado como indicativo de uma certa personalidade regional, tida como comum a quem era oriundo de uma dada àrea. Esses estereótipos, frequentemente referidos nas composições do Palito Métrico, podem ser vistos como factor discriminatório, mas também como sinal de que os estudantes de um determinado local, independentemente de viverem em grupos ou não, tendiam a ser vistos e reconhecidos a partir de uma macro identificação comum.

Em sua famosa memória sobre o melhoramento dos domínios lusitanos na América, de 1797, D. Rodrigo de Souza Coutinho, ministro e secretário de estado da Marinha e Domínios Ultramarinos, exortava a que os portugueses "nascidos nas quatro partes do mundo" se julgassem somente portugueses,

\footnotetext{
${ }^{26}$ Palito Métrico..., cit., p.168.

${ }^{27}$ FONSECA, Ferando Taveira da - A Universidade..., cit., p. 335.
} 
lembrando-os da fortuna de pertencer a uma monarquia que reunia num só todo, partes tão diferentes. À época dessa exortação, muitos dos alunos luso-brasileiros matriculados na Universidade nos primórdios após a reforma de 1772 já se haviam tornado profissionais, alguns a serviço da Coroa. O ministro de D. Maria I dirigia-se, especialmente, aos súbditos das "províncias da América que se denominam com o nome genérico de Brasil", reforçando sua decidida opção pelo desenvolvimento dessa parte do império como via para o enriquecimento de Portugal ${ }^{28}$.

Vale lembrar que, nesse período, julgar-se português não excluía a possibilidade do indivíduo conviver com outros níveis de identificação, conforme assinalaram Ana Cristina Nogueira da Silva e António Hespanha, a propósito da estrutura da identidade portuguesa na sociedade do Antigo Regime $^{29}$. Estes autores, imaginando uma escala de instâncias identitárias, observaram que, para além de uma matriz católica, europeia e hispânica que perpassava pela a identidade portuguesa, conviviam e se cruzavam com estas, "ao nível de círculos mais restritos de sociabilidade", outros índices identitários que, interiorizados, constituíam traços específicos de pertença não desprezíveis. No nível das "identidades particulares”, parentes, patrícios (no sentido de conterrâneos) e pares teriam constituído redes se sociabilidade de nítida operacionalidade social. Num outro plano, os portugueses também se reconheciam, ainda, como pertencentes a uma "pátria chica", conceito que estes historiadores utilizam para indicar o sentido de identificação dos moradores de uma determinada vila, cidade, ou região do Reino.

Até fins do século XVIII, a palavra pátria foi mais frequentemente usada como sinónimo do local de origem, da terra de onde se é. Afirma António de Oliveira que:

"Embora a Almedina constituísse o centro da morada dos estudantes, havia uma certa tendência para se agruparem de acordo com

${ }^{28}$ COUTINHO, Rodrigo de Souza - Memória sobre o melhoramento dos domínios de Sua majestade na América in Textos políticos, económicos e financeiros. 1783-1811. Lisboa: Banco de Portugal, 1993, tomo 3, p. 48-49.

${ }^{29}$ SILVA, Ana Cristina Nogueira e HESPANHA, António Manuel - A identidade portuguesa in MATTOSO, José (dir.) - História de Portugal. Lisboa: Editorial Estampa, 1992, vol. 4, p. 19-37. 
as proximidades geográficas das origens (...). Para certos efeitos (...), havia como que uma organização de pátrias, de regiões de nascimento." ${ }^{30}$

Este mesmo autor verificou em suas pesquisas que a região de origem dos estudantes costumava ser um pretexto para o estabelecimento de laços de solidariedade.

"A solidariedade das origens, com sociabilidade ajuramentada, encontramo-la entre os alentejanos, residentes no bairro de S. Pedro, "no mais alto da Couraça de Lisboa, onde chamão o bairro do Alentejo". Unida encontramos, igualmente a Província da Beira, devota de Nossa Senhora da Estrela. Espaços de sociabilidade documentados, um e outro, sintomaticamente por desacatos à ordem, muitas vezes companheiros da festa." ${ }^{\prime 1}$

O conceito de "pátria chica" (pequena pátria) presta-se, talvez melhor do que qualquer outro, para indicar os diferentes segmentos pelos quais estudantes ultramarinos se distinguiam entre si e se diferenciavam dos demais alunos de Coimbra. Os jovens estudantes luso-brasileiros, egressos de diferentes "províncias da América", muitas vezes se reconheciam e eram identificados a partir da sua região de nascimento. Assim, por exemplo, um nascido em São Paulo era paulista, se reconhecia como tal e, de alguma forma, não se confundia com o mineiro das Minas Gerais ou o baiano da Bahia. Para efeito de identificação e auto-identificação, a terra de origem, ou "pátria chica", mostrou ser mais operacional que o designativo genérico de brasileiro ou português da América, como também foi usado.

No caso dos estudantes do ultramar, a pertinência da utilização do conceito de "pátria chica" justifica-se pela emergência de seu significado em textos tão espontâneos quanto os do Palito Métrico. As composições reunidas nesta miscelânea jocoso-satírica foram produzidas no interior da comunidade estudantil, para ela se dirigiam e, nesse sentido, podem ser

\footnotetext{
${ }^{30}$ OLIVEIRA, António - O quotidiano..., cit., p. 624.

${ }^{31}$ Idem, p. 624.
} 
vistas como falas entre pares. Entretanto, é notório o reconhecimento pelos autores da existência de uma não homogeneidade entre aqueles "iguais". O local de origem foi frequentemente utilizado como factor de diferenciação entre os estudantes, sendo, por outro lado, vector de formação de grupos de convivência. Conforme se pode depreender das composições do Palito Métrico, aos originários de cada uma das diferentes "pátrias chicas" correspondiam estereótipos que os autores daqueles textos estudantis pretendiam compartilhar dentro do universo académico.

Sob pseudónimo de Bernardino de Albuquerque e Faro, um suposto estudante da Faculdade de Leis publicava no Palito Métrico a Carta guia para novatos. A linguagem chistosa em que são escritos os versos da Carta não diminui seu valor, antes dá visibilidade a um reconhecido arquipélago de identificações, mapeando para o recém chegado os saberes do veterano a recomendar a convivência com seus iguais como o porto seguro do caloiro. Justifica-se a citação, apesar de longa:

“[...] não tenhas nunca sociedade com quem destes contornos for nativo[...]

Isto mesmo usarás c'o Brasileiro, Que tem velhacaria, e muita treta; E se vires que é filho de mineiro, Arreda-te já dele, que é forreta [...] Acompanha, se queres, c'os do Porto, O braguês arrenega, que este é vário [...]

Acompanha com gente de Lisboa, Que esta menos má é do que é boa.[...]

Conversarás com quem for teu natural, Vizinho, conhecido, ou grande amigo [...]" ${ }^{32}$.

Numa outra poesia satírica da época aparece novamente a designação geral complementada por uma específica.

${ }^{32}$ Carta de guia para novatos, vida importante, ou química proveitosa, que um tratante envia a um amigo seu para cursar a universidade de Coimbra com grandeza na côdea, e chelpa in Palito Métrico..., cit. p. 193-215. 
"Fujamos, Delmira amada,

De tudo que he Brazileiro:

E dos filhos da Bahia

Devemos fugir primeiro." 33

Interessa notar como "mineiro" e "filho da Bahia" foram destacados do "brasileiro", tomado na sua generalidade. De alguma forma, no imaginário estudantil setecentista, o termo mais geral "brasileiro" continha os designativos regionais específicos "mineiro ou baiano", do mesmo modo que, entre os reinóis, os do Porto se distinguiam dos de Braga ou dos de Lisboa.

Por outro lado, ao contrário do que alguma historiografia recente quer fazer crer como anacronismo, a designação "brasileiro" foi frequentemente utilizada no século XVIII para se referir aos nascidos no Brasil. Por ser literatura burlesca, as abundantes ocorrências do termo no Palito Métrico, não devem ser menosprezadas. Ao invés, atestam o uso coevo do termo na linguagem coloquial do período. Isto contraria frontalmente certas correntes ortodoxas da historiografia brasileira, que rejeitam liminarmente o uso do patronímico "brasileiro" para os naturais da América Portuguesa, em completo desacordo com o que mostram as fontes. Em seu lugar, dizem, seria mais prudente empregar luso-brasileiro, brasílico e mazombo.

\section{A todos causava grande gosto e admiração}

Entre a chegada a Coimbra, as dificuldades de adaptação ao novo meio, a aprendizagem das formas de viver estudantil (dentro e fora da Universidade), e a cerimónia da tomada dos graus como última etapa do convívio académico, um longo percurso de vivências era percorrido pelo estudante. Ao graduar-se, já não era o mesmo da chegada. Além do prestígio social que significava possuir um título de bacharel ou de doutor, a honra de ter

${ }^{33}$ Discurso que fizerao duas senhoras portuguezas depois de lerem o papel dos Conselhos que deu hum brazileiro a todos os seus patricios... Dialogo entre Marcina e Delmira. Lisboa: na Officina de João Antonio da Silva, 1778. Trata-se de uma resposta a cordel intitulado Conselhos que dá hum Brazileiro Veterano a todos os seus Patricios que chegarem a esta Corte. Lisboa: na Officina de Francisco Sabino dos Santos, 1778. 
passado pela Universidade era extensiva à família do graduado. Disso estava ciente António, quando escrevia ao pai: "depois de passados (os anos em Coimbra), tem VM o gosto, e glória de ter um filho que seja a honra, e lustre de toda a sua geração, pois até agora não tivemos nela pessoa ou parente que passasse a estudar a esta Universidade, e com suas letras honrasse a sua progênie." ${ }^{34}$ Reconhecido factor de elevação de estatuto social, o título universitário alcançado em Coimbra constituía um passaporte eficaz para ingressar noutros patamares de consideração social. De entre eles, o próprio corpo docente da Universidade, do qual alguns brasileiros setecentistas vieram a fazer parte. Alexandre Rodrigues, como demonstrador da cadeira de História Natural; José da Silva Lisboa, como substituto das cadeiras de Grego e Hebraico ${ }^{35}$; Vicente Coelho Seabra Silva Telles, como lente substituto extraordinário de Química e substituto de Botânica e Zoologia ${ }^{36}$, para ficar apenas em alguns exemplos.

Embora não estejam disponíveis documentos que permitam maiores aproximações ao quotidiano dos estudantes brasileiros em Coimbra, algumas indicações dão a perceber a sua atuação como grupo. No do dia 22 de Setembro de 1772, todos os sinos da cidade entraram em repique festivo anunciando a chegada do Marquês de Pombal para a entrega oficial dos Estatutos da reforma da Universidade. Nessa noite, espalharam-se por toda a cidade fantásticas luminárias. As memórias contemporâneas referem o deslumbramento causado pela iluminação "que fizeram os estudantes brazileiros com effeitos de perspectiva, representando a Sciencia cahindo, e entre nuvens sahindo uma mão que a sustenta pelo braço." ${ }^{37}$ Os brasileiros tinham um motivo muito particular para festejarem o acontecimento: o reitor escolhido para dirigir a nova Universidade, Francisco de Lemos de Faria Pereira Coutinho, era natural do Brasil.

${ }^{34}$ RUSSEL-WOOD, A. J. - Relato..., cit., p. 20, nota 19.

${ }^{35}$ LISBOA, Baltasar da Silva - Discurso histórico, político e econômico dos progressos, e estado atual da Filosofia Natural portuguesa, acompanhado de algumas reflexões sobre o Brasil. Lisboa: Oficina de Antonio Gomes, 1786.

${ }^{36}$ GOUVEIA, António Jorge Andrade de - Químico esclarecido luso-brasileiro: Vicente de Seabra, 1764-1804. Memórias da Academia das Ciências de Lisboa, Classe de Ciências, 21 (1976-1977) 10.

${ }^{37}$ BRAGA, Teófilo - História da Universidade, cit., p. 428. 
Mais tarde, os alunos brasileiros de Vandelli foram protagonistas de outro espetáculo público. A Gazeta de Lisboa noticiou a primeira experiência aerostática realizada em Coimbra, encomendada por Vandelli a seus alunos de Química. Entre os autores da "Machina aerostatica" estavam dois brasileiros: José Álvares Maciel e Vicente Coelho de Seabra. À subida do balão piramidal assistiram o "reitor, com todo o corpo académico, nobreza e povo", sendo os autores da experiência muito aplaudidos. Para além do interesse que essas experiências despertavam no público, como espetáculo visual de grande impacto, tais atividades extra-muros faziam parte do curriculum académico e eram um estímulo para os estudantes aprimorarem seus conhecimentos técnico-científicos. Após a experiência com o balão de papel, que se rompera à primeira tentativa, projectou-se a construção de um outro, desta vez em "tafetá envernizado com uma gomma elastica"38, inovação descoberta pelos jovens aprendizes. Daí por diante, os estudantes de Filosofia Natural promoveram, com sucesso, exibições em várias ocasiões festivas. As notícias da Gazeta indicam que, no ano de 1784, "se formaram pelos Estudantes Naturalistas várias máquinas aerostáticas, as quais todas de elevaram a diferentes alturas". ${ }^{39}$ Essas máquinas maravilhosas funcionavam como instrumentos de divulgação e vulgarização do saber científico e talvez tivessem mesmo o sentido de peças publicitárias aéreas de um certo “marketing” científico da época.

Em 1 de junho de 1785, Portugal festejava o casamento dos infantes de Portugal e Espanha. A Universidade comemorou a efeméride com uma grande queima de fogos de artifício, descrita pela Gazeta de Lisboa:

Na varanda do Palácio [no prédio da Universidade], houve uma fonte de fogo, que representava 22 repuxos, formados por outros tantos canudos de cobre com diferentes direções: este fogo era produzido por gás inflamável, separado pelo método de Priestly, o qual formava uma chama contínua, cintilante, e azulada: e diminuindo-se depois a força do fogo, apareciam sobre as bocas dos tubos umas luzes

\footnotetext{
${ }^{38}$ Gazeta de Lisboa, seg. supl. ao n.28, 17 de Julho de 1784.

${ }^{39}$ Gazeta de Lisboa, seg. supl. ao n.34, 28 de Agosto de 1784.
} 
representando grandes e perfeitas safiras: fenômeno que se deve a invenção ao laboratório da Universidade" ${ }^{40}$

É bem provável que estudantes brasileiros, discípulos de Vandelli e Dala Bella das Faculdades de Matemática e Filosofia, estivessem envolvidos com essas demonstrações feéricas e espetaculares do saber científico. Sabe-se da especial apetência dos brasileiros setecentistas por aqueles cursos e das atividades desenvolvidas por eles junto as seus mestres no Laboratório de Física da Universidade.

"Nascimentos, aniversários, casamentos, coroações e todos os acontecimentos festivos ligados à sociabilidade cortesã eram pretexto para a festa $\mathrm{e}$ para o espetáculo que devia ser exibido, mobilizando grande quantidade de pessoas" A Universidade de Coimbra não se furtava, nessas oportunidades, de também fazer exibições cuja "intenção celebrativa acabava, assim, por tornar visível o poder da ciência e da instituição que a ministrava"

Na edição de 16 de julho de 1785 da Gazeta de Lisboa encontraremos a Universidade de Coimbra festejando o aniversário do rei D. José com um espetáculo de pirotecnia. Das sete horas da tarde às duas da manhã, arderam 150 chamas em várias direções sobre as quais uma águia lançava fogo pelo bico e pelas pontas das asas, que "a todos causava grande gosto e admiração". ${ }^{42}$ A participação dos estudantes nesses espetáculos e seus preparativos envolvia grande dose de entusiasmo e emulação, constituindo momentos privilegiados de aprendizagem associado ao carácter lúdico e de sociabilidade académica.

\section{Aprender viajando}

Para além das oportunidades de demonstrar publicamente as maravilhas da ciência que as ocasiões festivas propiciavam, os estudantes brasileiros passavam também por um processo de ensino prático que, no caso dos

\footnotetext{
${ }^{40}$ Gazeta de Lisboa, seg. supl. ao n.24, 18 de Junho de 1785.

${ }^{41}$ GOUVEIA, Isabel de Barros Amaral Marques - Fantasia, ciência e espetáculo em Portugal no século XVIII. Coimbra: Universidade de Coimbra, 2000.

${ }^{42}$ Gazeta de Lisboa. Seg. supl. ao no 27, 16 de Julho de 1785.
} 
estudantes de História Natural, se consubstanciou em programas de treino de campo planeados por Vandelli, segundo o exemplo de Lineu ${ }^{43}$. O mestre italiano defendia a realização de um projecto de reconhecimento das potencialidades naturais úteis ao desenvolvimento económico do Reino, que seria efectivado em etapas sucessivas: primeiro, realizar uma viagem filosófica pelo Reino, e depois, em seus domínios ${ }^{44}$.

O interesse pelo adestramento científico dos alunos de História Natural, Física e Química era preocupação também das instâncias superiores da Universidade de Coimbra. Em 1779, concretizando as orientações do ensino experimental presente nos Estatutos, a Congregação Geral das Faculdades de Filosofia, Matemática e Medicina determinava que professores e alunos realizassem viagens de estudo. Domingos Vandelli e Dalla Bella foram encarregados de elaborar o plano de execução das mesmas, cujos participantes tinham a obrigatoriedade de apresentar relatórios escritos e de encaminharem à Faculdade os produtos que colectassem ${ }^{45}$.

Pertencendo à primeira leva de alunos brasileiros da Coimbra reformada, Alexandre Rodrigues Ferreira e João da Silva Feijó realizariam juntos seu treinamento de campo na região de Buarcos, onde examinaram as minas de cobre perto do Cabo Mondego. Logo após se terem formado, Alexandre Rodrigues Ferreira, João da Silva Feijó, Manuel Galvão da Silva e José Joaquim da Silva foram ingressaram no serviço régio, passando a trabalhar na organização do gabinete e Jardim Botânico da Ajuda, em Lisboa.

Ao mesmo tempo, nas primeiras viagens aos arredores de Coimbra, faziam parte do treinamento profissional dos naturalistas, cumpriam o objetivo de recolher espécimes para o Museu da Universidade, além de servirem o objectivo utilitário de descobrir e avaliar os recursos económicos

${ }^{43}$ O naturalista sueco Carl Linneu sutentava que o naturalista precisava de conhecer os recursos naturais de seu próprio país antes de visitar outros, e que o conhecimento completo dos recursos e potencialidades do país era a chave do desenvolvimento económico. LINEU Caroli - Oratio de Necessitate Peregrinationum intra Patriam. Lugduni Batavorum: C. Haak, 1743. Sobre o carácter nacionalista sueco do pensamento de Lineu, ver KOERNER, Lisbet - Linnaeus; Nature and nation. Cambridge: Harvard University Press, 2000.

${ }^{44}$ VANDELLI, Domingos - Memória sobre a necessidade de uma viagem filosófica feita no Reino, e depois nos seus domínios in Aritmética Política, Economia e Finanças, 1770-1804. Lisboa: Banco de Portugal, 1994, p. 21-45.

${ }^{45}$ CRUZ, Lígia - Domingos Vandelli, alguns aspectos da sua actividade em Coimbra. Separata do Boletim do Arquivo da Universidade de Coimbra. (1976). 
dos terrenos circunvizinhos a Coimbra. Os bispos de Coimbra eram, também, senhores das terras de Coja e Avô. O brasileiro D. Francisco de Lemos, bispo reformador, prontamente colocou as terras desse senhorio no rol das regiões a serem visitadas pelos estudantes e professores da Universidade. Desse projecto tomou parte Baltasar da Silva Lisboa, recebendo a incumbência de examinar as minas (chumbo, ferro, cobre, prata, ouro, antimônio e enxofre) de $\mathrm{Coja}^{46}$. Seu companheiro no estudo das minas foi outro estudante baiano, Joaquim de Amorim e Castro.

Já como professor em Coimbra, o doutor Joaquim Veloso de Miranda foi um dos encarregados para, junto com outros naturalistas, fazer investigações nas Serras da Estrela e Gerez, pelo que seriam remunerados com "as sobras dos partidos filosóficos" ${ }^{47}$. Também remunerado foi José Álvares Maciel para, em 1784, prosseguir com as investigações na Serra da Estrela, missão em que foi acompanhado por um herborista. Durante sessenta e dois dias, ambos estiveram explorando aquela região, recebendo, respectivamente, $48 \$ 000$ e $25 \$ 000$ réis $^{48}$.

Assim, perfeitamente inseridos nesse projecto, os alunos brasileiros de Vandelli foram, sucessivamente, enviados a várias regiões nas imediações de Coimbra, como parte de sua formação académica e início de actividades profissionais. O empenho de Vandelli para que seus alunos se dedicassem à História Natural, juntamente com a possibilidades que estes anteviam de conseguir um emprego régio, certamente teria contribuído para que estudantes de outras áreas viessem a actuar como naturalistas.

A despeito do que se possa imaginar, não era invulgar estudantes de outras áreas optarem pelas actividades próprias do naturalista. Em 1799, um bacharel formado em Direito, "natural do Brasil, que sabe muito bem desenhar as plantas" oferecia-se a Felix de Avelar Brotero, professor de Botânica na Universidade de Coimbra, para seguir a Botânica alguns anos, manifestando seu desejo de "ir depois servir de alguma coisa no seu país".

${ }^{46}$ LISBOA, Baltasar da Silva - Viagem mineralogico botanica, etc de Coimbra a Coja. Jornal Enciclopedico. Lisboa (1789), ou Biblioteca Geral da Universidade de Coimbra Viagens feitas à ordem do Exmo. Senhor Bispo Conde no país de Coja em o ano de 1782, códice 2549.

${ }^{47}$ CRUZ, Lígia - Domingos Vandelli..., cit., p. 14.

${ }^{48}$ Idem, p.15. 
Em carta ao ministro D. Rodrigo, Brotero mostrava interesse em satisfazer os anseios do estudante para tê-lo como "desenhador", durante o tempo em que fizesse o seu curso, pelo que solicitava a "proteção" do ministro, "para que seu pai, que assiste no Rio de Janeiro, lhe mande para isso continuar as mesadas." 49 Pelo que se depreende desse documento, os alunos brasileiros percebiam que abraçar as Ciências Naturais era uma das vias para voltar para a terra com um emprego garantido. A "proteção" do ministro significando a garantia de uma colocação na colónia.

Em 1776, aos dezesseis anos, provavelmente recém chegado do Brasil, o baiano Joaquim Amorim de Castro entrava na Universidade de Coimbra. Sua trajectória acadêmica não difere muito da de outros brasileiros do seu tempo que, optando pelo curso de Direito, acabaram por desenvolver forte atracção pelos estudos de História Natural. Amorim e Castro frequentou os cursos de Filosofia e Matemática na categoria de obrigado, tendo sido, durante esse período, aluno de Vandelli. Como tarefa da disciplina do mestre italiano, Amorim e Castro foi encarregado de observar as minas de carvão da Figueira da Foz. Deste trabalho de campo resultou uma Memória, na qual se evidencia o carácter prático e experimental do ensino da História Natural, tanto quanto o princípio utilitário da exploração dos recursos naturais, característico das explorações naturalistas do século XVIII português ${ }^{50}$. No Laboratório de Química, Amorim e Castro teria assistido a uma experiência de extracção de caparrosa do carvão de pedra, realizada por seu conterrâneo e colega Baltasar da Silva Lisboa. Essa experiência teria valido ao estudante para, ao observar a mina da Figueira, propor a instalação contígua de uma fábrica de extração daquele derivado do carvão. Já no caminho de volta a Coimbra, sua curiosidade científica o teria levado a verificar a existência de uma mina de chumbo sobre a qual tivera notícia. Acabou por descobrir indícios de um rico e profundo manancial de carvão de pedra inexplorado. Acreditando nas possibilidades exploratórias da nova mina e cheio de interesse pela sua "descoberta" Amorim e Castro se dizia

${ }^{49}$ Carta de Félix de Avelar Brotero para D. Rodrigo de Sousa Coutinho, datada de 4 de novembro de 1799, ver Arquivo Histórico Ultramarino - Reino 1961.

${ }^{50}$ Academia das Ciências de Lisboa - CASTRO, Joaquim de Amorim e - Memória de Joaquim de Amorim e Castro mandado pelo seu sábio Mestre o Senhor Doutor Domingos Vandelli, a observar o aumento da mina da Figueira, série azul, códice 376. 
excitado por examiná-la com mais vagar "depois que acabar de fazer os meus atos". Ao voltar ao Brasil, este jurista viria a ocupar o cargo de juiz de fora de Cachoeira, na Bahia, onde continuaria a exercitar seus conhecimentos de História Natural e a escrever memórias sobre o aproveitamento económico das produções locais.

O baiano Baltasar da Silva Lisboa matriculou-se em Filosofia no mesmo ano que seu conterrâneo Joaquim Amorim de Castro e, tal como este, formou-se em Direito. Pelo levantamento de brasileiros matriculados em Coimbra, elaborado por Francisco de Morais, Baltasar teria feito os exames do terceiro ano de Filosofia em 1782. Nesse mesmo ano, foi encarregado de percorrer as terras do bispo, em Coja, para realizar investigações mineralógicas. Como muitos dos brasileiros que passaram por Coimbra após a reforma, Baltasar teria desenvolvido o gosto pelas actividades de naturalista. Em 1786, o jovem "doutor em Leis" oferecia ao príncipe regente seu Discurso historico, politico e economico dos progressos, e estado actual da Filosofia Natural Portuguesa, acompanhado de algumas reflexões sobre o Brasil. Nesta monografia, Baltasar procurou traçar uma perspectiva histórica do interesse dos portugueses pela História Natural. Recuando ao tempo das explorações de Garcia de Orta e Duarte Macedo, a breve retrospectiva avança até chegar ao século XVIII, registando aí a actividade colecionista disseminada nos círculos eruditos durante o reinado de D. João V, e, já no reinado de D. José, o desenvolvimento dos estudos da História Natural na Universidade. Baltasar destacava o interesse que os estudos da História Natural despertavam nos estudantes de Coimbra: "foram sempre muito frequentadas as aulas da História Natural, e dos outros ramos da Filosofia, porque inculcando eles por si mesmos suas vantagens, atraiam o ânimo de alguns mancebos patriotas à sua aplicação", afirmando que, por essa razão, "distinguiram-se muitos estudantes que suposto seguissem o objeto de outras ciências, amavam contudo as íntimas relações desta

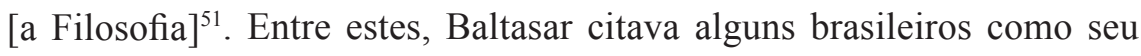
irmão José da Silva Lisboa, Estácio Gularte Pereira, Joaquim Veloso de Miranda, Alexandre Rodrigues Ferreira "e os companheiros das expedições filosóficas" e Joaquim de Amorim e Castro. Na segunda parte do referido

${ }^{51}$ LISBOA, Baltasar da Silva - Discurso..., cit., p. 13-14. 
trabalho, dedicada a reflexões sobre o Brasil, o autor propugnava a actuação de "Magistrados Filósofos" como agentes privilegiados de indução do progresso e aproveitamento económico das potencialidades da colónia do Brasil. Para além de monografia temática elaborada por um estudioso da Filosofia Natural, o Discurso se pode ser lido como uma apresentação das credenciais do autor, acompanhada de proposta de acção para uma actuação possivelmente desejada. O facto é que Baltasar acabou por ser enviado ao Brasil, aonde viria a exercer como um "Magistrado Filósofo" nas funções de ouvidor e conservador das Matas de Ilhéus.

Essas viagens e investigações experimentais, aliadas às práticas de laboratório na Universidade integravam o programa de ensino de Vandelli, voltado para a articulação da teoria com o trabalho empírico das observações de campo. A vivência dos estudantes, durante esse período, consolidaria a sua instrucção, bem como daria sentido utilitário ao seu trabalho. Dessa leva de estudantes brasileiros das últimas décadas do século XVIII saíram os primeiros naturalistas de formação universitária do Reino, vários deles aliando as actividades científicas às burocráticas de funcionários da Coroa, na metrópole e no ultramar. O volume das investigações levadas a efeito pelos cientistas brasileiros, bem como a abundante produção científica daí decorrente constituem, na maior parte dos casos, as primeiras informações de carácter técnico-científico geradas sobre diversas regiões do Reino e, principalmente de suas colónias. Esse legado, ainda insuficientemente estudado em seu conjunto, vem merecendo a atenção dos investigadores da História das Ciências no Brasil. Contudo, a produção dos brasileiros setecentistas, que não se restringe às suas experiências em solo brasileiro ${ }^{52}$, propicia abordagens múltiplas, e aponta para direcções que vão além do seu conteúdo técnico-científico.

${ }^{52}$ Ver PEREIRA, Magnus Roberto de Mello - Brasileiros a serviço do Império; a África vista por naturais do Brasil, no século XVIII. Revista Portuguesa de História. 33 (1999) 153-190. 